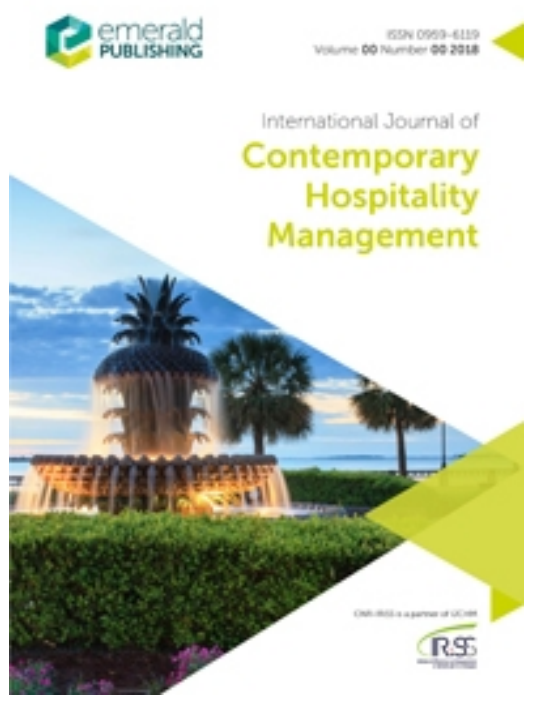

\title{
Spicing Up Hospitality Service Encounters: The Case of Pepper $^{\mathrm{TM}}$
}

\begin{tabular}{|r|l|}
\hline Journal: & International Journal of Contemporary Hospitality Management \\
\hline Manuscript ID & IJCHM-07-2020-0739.R4 \\
\hline Manuscript Type: & Original Article \\
\hline Keywords: & $\begin{array}{l}\text { service robot adoption, Pepper } \\
\text { encounter, Design, human-robot interaction }\end{array}$ \\
\hline \multicolumn{2}{|l}{} \\
\hline
\end{tabular}

\section{SCHOLARONE \\ Manuscripts}




\section{Spicing Up Hospitality Service Encounters: The Case of Pepper ${ }^{\mathrm{TM}}$}

\section{Purpose}

This paper aims to explore the implications of integrating humanoid service robots into hospitality service encounters by evaluating two service prototypes using Softbank Robotics' popular service robot PepperTM: (1) to provide information (akin to a receptionist) and (2) to facilitate order-taking (akin to a server). Drawing both studies together, the paper puts forward novel, theory-informed yet contextrooted design principles for Humanoid Robot Adoption in Hospitality Service Encounters (HuRAHSE).

\section{Design/methodology/approach}

Adopting a multiple method qualitative approach, two service prototypes are evaluated with hospitality and tourism experts $(N=30$, prototype 1$)$ and frontline hospitality employees $(N=18$, prototype 2$)$ using participant observation, in situ feedback, semi-structured interviews, and photo elicitation.

\section{Findings}

The adoption of humanoid service robots in hospitality is influenced by four layers of determinants: contextual, social, interactional, and psychological factors, as well as extrinsic and intrinsic drivers of adoption. These empirical findings both confirm and extend previous conceptualizations of humanrobot interaction (HRI) in hospitality service.

\section{Originality}

This paper presents one of the first empirical studies on HRI in hospitality service encounters using Softbank Robotics' Pepper ${ }^{\mathrm{TM}}$. In doing so the paper presents a novel framework for service robot adoption rooted in first-hand user interaction as opposed to previous, theory-driven conceptualizations of behavior or empirical studies exploring behavioral intention.

\section{Research limitations/implications}

Despite using photo elicitation to evoke insight regarding the use of different types of service robots in hospitality, the paper mostly focuses on anthropomorphized service robots such as Pepper ${ }^{\mathrm{TM}}$.

\section{Practical implications}

Adopting humanoid service robots will transform hospitality operations, whereby the most routine, unpleasant tasks such as taking repeat orders or dealing with complaints may be delegated to service robots or human-robot teams.

\section{Social implications}

Working with and receiving service from Pepper ${ }^{\mathrm{TM}}$ changes the service encounter from direct practical, technical considerations to more nuanced social and psychological implications, particularly around feelings of self-esteem, social pressure, and social judgment. 


\section{Spicing Up Hospitality Service Encounters: The Case of Pepper ${ }^{\mathrm{TM}}$}

\subsection{Introduction}

Hospitality is a notoriously difficult business. Customer preferences are in constant flux, competition is fierce, and the sector is characterized by thin margins (Davis et al., 2018). A key part of the challenge is people, whereby hospitality companies rely on a continuous supply of labor to produce and provide a myriad of services for their guests. From baristas pulling shots to sommeliers serving wine, the sector employs over 3.2 million or roughly $10 \%$ of all workers in the UK (UKHospitality, 2020). Most developed countries see a similar picture, while the relative importance of hospitality employment in developing countries is typically even higher (Baum, 2015). Despite the sector's high reliance on human labor, the industry observes high turnover rates, and because of increased consumer demand, even labor shortages (Tuomi et al., 2020).

To address these issues, forward-looking businesses are turning towards technology to cut costs, increase efficiency, and delight customers in novel ways (Ashcroft et al., 2019). Recent advancements in service robotics offer the most concrete example of this, whereby hospitality employees are directly supported or substituted by artificially intelligent service technology (Tuomi, Tussyadiah and Stienmetz, 2020). For instance, at Tokyo's Henn-na Café customers are able to place, pay, and receive their order with no human interaction, while at Boston-based Spyce service offerings are produced and provided through a human-robot collaborative effort: robot measures and cooks ingredients, as well as cleans the cooking equipment, while a human employee takes care of garnishing the dish and serving it to the customer. The rise of service robots in hospitality operations requires a careful consideration of how these technologies transform services, and as a result, how the way service processes and service experiences are designed (Tung and $\mathrm{Au}, 2018$; Lu, Zhang and Zhang, 2021).

One of the cornerstones of service management research is the service encounter, that is, the dyadic interaction between customers and service providers (Lin and Mattila, 2010). For decades, this interaction took place between humans. However, the use of service robotics poses to change the conventional notions of service encounter, whereby an increasing portion of the encounter is formed of human-robot interaction (HRI) (Gursoy et al., 2019). Besides supporting or substituting service employees, service robots may improve the service offering by streamlining common friction points or standardizing service delivery. While other technological innovations, such as self-service kiosks, may also streamline and standardize parts of the service encounter, they do so in a one-dimensional, static manner. Service robots, particularly anthropomorphized robots, add an unforeseen "social" layer to the mix (Mori, 1970; Belanche et al., 2019; Belanche, Casaló and Flavián, 2020a).

Even though promising steps in trying to understand the new service interaction between customers and service robots have been undertaken, for example, in the context of hotels (Tussyadiah and Park, 2017) or restaurants (Belanche, Casaló and Flavián, 2020b), less emphasis has been given to studying the use of service robots from service employees' point of view. Further, previous studies have often been hypothetical in nature, measuring willingness to use or interact with a service robot in a scenario (e.g., based on a written description or a photograph/video of a service robot) rather than actual usage behavior (Belanche, Casaló and Flavián, 2020a; 2020b).

To address this gap in extant hospitality literature, a two-stage qualitative field study was conducted using Softbank Robotics' humanoid service robot Pepper ${ }^{\mathrm{TM}}$, whereby Pepper ${ }^{\mathrm{TM}}$ was programmed to interact with humans in two relatively common hospitality use-settings: (1) welcoming guests and providing basic information of a location (akin to a receptionist), and (2) taking food and drink orders 
(akin to a server). The study aims to explore how a humanoid service robot (e.g. Pepper ${ }^{\mathrm{TM}}$ ) could be integrated into hospitality service encounters, and what the subsequent implications on hospitality management and employment might be. In particular, the study aims to address the following research question: What are the service interaction design implications of automating hospitality service encounters with a humanoid robot? To answer this question, the study draws on seminal theories on service and human resource management as well as HRI: Ritzer's (1998) McDonaldization, Hackman and Oldham's (1980) Job Design Theory, and Mori's (1970) Uncanny Valley Theory, and makes a unique contribution to hospitality scholarship by putting forward design principles for Humanoid Robot Adoption in Hospitality Service Encounters (HuRA-HSE).

\subsection{Service robots and HRI}

Robots are generally divided into industrial and service robots, depending on their use-context. Industrial robots work in well-defined, confined environments with limited or no human contact, such as in factories or at mining sites. On the other hand, service robots navigate and take action in dynamic human environments, e.g. restaurants (Rubio, Valero and Llopis-Albert, 2019). Given the varying useenvironments of robots, Wirtz et al. (2018) define service robots as "system-based autonomous and adaptable interfaces that interact, communicate, and deliver service to an organization's customer" (p. 909). The ensuing human-robot interaction is a booming research discipline which explores the intersection of robot systems and human behavior. As a field of study, HRI is inherently multidisciplinary, combining areas as diverse as psychology, engineering, computer science, and others. However, despite the diversity of disciplines involved, Marsh and Meagher (2016) see that the vast majority of research on HRI tends to emphasize action on rather than action with a robot agent. They argue that HRI studies are often driven by an engineering-mindset, which explores interaction in relation to functional outcomes such as reaction time or task completion rate rather than psychological drivers of behavior. One of the most well-recognized HRI theories from a social science perspective is the Uncanny Valley Theory suggested by Mori (1970). The theory postulates that humans tend to anthropomorphize machines, and that as a machine's human-likeness increases, so does affinity towards it. However, machines that are perceived as very human-like but not quite human fall into what is known as the Uncanny Valley, an area of uncomfortable eeriness.

As service robot applications have become more pervasive, studies exploring human-robot interaction as well as the impacts of robotization on hospitality management have started to emerge. Some studies have compared how specific robot design types, such as anthropomorphic or non-humanoid robots, impact services (Onyeulo and Gandhi, 2020). Looking at service robot use in hotels and restaurants, Tuomi, Tussyadiah, and Stienmetz (2020) concluded that anthropomorphized robots were mostly used in customer-facing tasks while non-humanoid robots were more common in back-of-house tasks. Distinguishing between different types of service tasks carried out by artificially intelligent agents, Huang and Rust $(2018$; 2021) arrived at four layers of intelligence: mechanical, analytical, intuitive, and empathetic intelligence. Noting that the vast majority of existing service robot applications fall within the first two layers of intelligence, Belanche, Casaló and Flavián (2020b) emphasized the importance of communicating the specific robot capabilities to consumers in order to better manage expectations in hospitality-centric HRI.

Complementing Huang and Rust's (2018) task-level view of service robotization, Ritzer's (1998) seminal theory of McDonaldization offers a macro-level view for examining the robotization of service encounters in hospitality. In his social critique mapping out the success of McDonald's, Ritzer (1998) referred to the systematic pursuit of a more standardized, optimized, reliable and thus predictive production system as 'McDonaldized'. In particular, a key tenet to McDonaldization is achieving a 
higher degree of control through replacing people with technology. Not only do people pale in comparison when it comes to their physique and mental prowess, they are also prone to human error and their performance (e.g., in terms of service quality) is highly variable (Choi, Mattila and Bolton, 2020). Even if a service organization tries to 'program' its staff to behave in a particular way through operational manuals or service scripting, ensuring perfect consistency is not only resource intensive but often impossible.

It can be argued that rather than trying to robotize humans, a more productive route might be humanizing robots and designing jobs around features that better reflect human, not robot capability. Building on Herzberg, Mausner, and Snyderman's (1959) Motivation Theory, Hackman and Oldham (1980) argue that jobs abound with repetitive, monotonous tasks tend to stifle employee motivation and decrease job satisfaction, whereas jobs that include a variety of tasks as well as challenge, autonomy, and active decision-making enhance motivation and lead to a feeling that work is enriching and empowering. Applying service robotics in hospitality contexts in a similar manner, that is, in a way that makes the best use of both human and machine capability, could help reduce the precarity often associated with working in the service industries (Baum, 2015), increase person-job fit (Oldham and Fried, 2016), and in doing so signal a move towards soft people management practices aimed at creating more 'decent' hospitality employment (Tuomi et al., 2020). However, determining the balance between different factors that influence HRI in the specific context of hospitality service, including tasks most suitable for robotization, is an area that is still in need of further study (Ivanov and Webster, 2019; Tussyadiah, 2020).

\subsection{Method}

In order to address the research question: "What are the service interaction design implications of automating hospitality service encounters with a humanoid robot?", this study employs a qualitative multi-method approach, which includes exploratory service experimentation (using two service prototypes) accompanied with observation, questionnaire, interview, and photo elicitation, in order to examine the phenomenon in a way that is holistic and retains meaning. First, to provide suitable settings for hospitality service encounters with service robots, two hospitality service prototypes were designed using service robot Pepper ${ }^{\mathrm{TM}}$. Pepper ${ }^{\mathrm{TM}}$ was selected for its popularity (Pepper ${ }^{\mathrm{TM}}$ is currently one of the most widely adopted service robots in the world) and its suitable base characteristics, including anthropomorphic design, expressive facial features, 20 degrees of freedom, a programmable Android tablet, as well as an intuitive software development kit (Pandey and Gelin, 2018). Pepper ${ }^{\mathrm{TM}}$ has a white body, is $1.2 \mathrm{~m}$ tall, and has a range of sensors for navigation and interaction, including two sonars, two infrared sensors, six lasers, a microphone, and six tactile sensors (Perera et al., 2017). As a research instrument, service prototypes seek to generate practical insight by presenting new ideas and concepts in a tangible form. They facilitate what Liedtka (2011) refers to as 'learning launches', that is, opportunities to test, develop and refine new ideas and service concepts in the real world. According to Rodgers and Milton (2011) service prototypes can be either focused (i.e., portraying a particular new element of a service in detail) or comprehensive (i.e., providing an overview of the entire new service offering or process). As the aim of the study was to explore the implications of integrating a humanoid service robot, Pepper ${ }^{\mathrm{TM}}$, as part of hospitality service interaction, a focused approach was adopted. As Pepper $^{\mathrm{TM}}$ is a conversational humanoid robot with limited capability for mobility and dexterity, it was deemed primarily suitable for application in customer-facing service encounters.

For the first service prototype, Pepper ${ }^{\mathrm{TM}}$ was programmed to interact with delegates during an academic conference focused on technology and tourism. The conference took place in the UK in January 2020. Following a purposive sampling strategy, the conference was deemed an ideal setting for testing 
Pepper ${ }^{\mathrm{TM}}$ because of its theme and diversity of participants (including hospitality and tourism scholars, practitioners, and technology developers). Participants were therefore recruited for their expertise throughout the 4-day conference. Altogether 30 participants (of which 13 were female) took part in the first service prototype (see Table I). Figure I presents an illustration of the setup of the first service prototype.

\section{PLEASE INSERT TABLE I ABOUT HERE}

\section{PLEASE INSERT FIGURE I ABOUT HERE}

After a brief introduction to the study, participants were invited to interact with Pepper ${ }^{\mathrm{TM}}$, which had been programmed to display the conference program on its tablet. Participants were able to navigate the program, as well as ask generic questions from PepperTM (e.g., "What's your name?" "How are you?" "Why are you here?"), through a combination of natural language (English-based voice recognition) and tablet interaction. The average interaction time per participant was $3 \min 25 \mathrm{sec}(S D: 3 \mathrm{~min} 14 \mathrm{sec}$, $C V: .95)$.

The interactions were observed, noting any apparent critical incidents. After the interaction participants were asked to verbally comment on any observed critical incidents and to fill in a short questionnaire administered on a tablet computer. The questionnaire captured demographic factors as well as presented participants with six items measured on a 5-point Likert scale. These explored (1) the naturalness and (2) the enjoyability of the experience. Participants were also asked to identify hospitality service encounters they saw as most suitable for using Pepper ${ }^{\mathrm{TM}}$. In particular, the researchers were interested in understanding for which types of service encounters most common in food service would Pepper ${ }^{\mathrm{TM}}$ be a good match: (3) welcoming guests, (4) taking orders, (5) serving food and drinks, or (6) facilitating payments. Of these, participants saw using Pepper ${ }^{\mathrm{TM}}$ for taking orders as its most suitable usage, while using Pepper ${ }^{\mathrm{TM}}$ to serve food and drinks was seen as least suitable. Using Pepper ${ }^{\mathrm{TM}}$ to welcome guests was seen as quite acceptable, along with taking payments with Pepper ${ }^{\mathrm{TM}}$.

Building on insights from the first service prototype, a second prototype was developed focusing on the dimension of hospitality service prototype 1 participants had perceived as most suitable for Pepper ${ }^{\text {TM}}$ : taking food and drink orders. To that end, Pepper ${ }^{\mathrm{TM}}$ was programmed to interact with participants in a simulated restaurant setting. A purposive sampling strategy was used again, this time targeting participants who were currently working in or had been previously employed by the food service sector. Targeting front-line hospitality professionals was expected to offer rich insight, as it allowed the participant to reflect on the HRI from both the employee and customer perspectives, i.e., on the operational implications of integrating Pepper ${ }^{\mathrm{TM}}$ as part of hospitality operations (participant leveraging their own experience as an employee), along with insight about the robotized service experience itself (participant reflecting on the encounter as a customer). Altogether 18 participants (of which seven were female) were recruited to take part in the second service prototype (see Table II). Figure II presents an illustration of the setup of the second service prototype.

\section{PLEASE INSERT TABLE II ABOUT HERE}

\section{PLEASE INSERT FIGURE II ABOUT HERE}

After a brief introduction to the study, participants were invited to interact with Pepper ${ }^{\mathrm{TM}}$, which had been programmed to display a restaurant menu on its tablet. The menu was inspired by a real à la carte 
restaurant menu, and included a selection of starters, mains, desserts, and drinks. Participants were able to navigate the menu using a combination of voice commands and touchscreen interaction, as well as ask Pepper ${ }^{\mathrm{TM}}$ some generic questions about the menu (e.g., "How are you?" "What would you recommend?" "What's the most popular dish?"). The user interface was designed so that participants could add (or remove) items from the menu to their 'shopping basket'. The menu items themselves prompted further interaction with participants, for example, when ordering wine, Pepper ${ }^{\mathrm{TM}}$ would ask what measure the participant would like, or when ordering a main dish, Pepper ${ }^{\mathrm{TM}}$ would inquire whether participants would like the normal or the vegan version of the dish. Once participants had decided what they would like to order, Pepper ${ }^{\mathrm{TM}}$ would prompt them to send their order to the kitchen, and when they did, Pepper ${ }^{\mathrm{TM}}$ wished them well and the service interaction ended.

The average interaction time per participant was $5 \mathrm{~min} 26 \mathrm{sec}(S D: 2 \mathrm{~min} 38 \mathrm{sec}, C V: .48)$. To mitigate for the Hawthorne Effect (Jones, 1992), i.e., the researcher's physical presence impacting the way in which participants interact with Pepper ${ }^{\mathrm{TM}}$, the service encounters were observed covertly from outside the room, through a window. As with the first prototype, critical incidents were noted. After the interaction was over, the researcher re-entered the room, debriefed the participant, and proceeded to conduct a semi-structured interview. The interviews lasted for 27 minutes on average. Questions were grouped into five categories, building on existing literature. First, to better understand the HRI itself, participants were asked to describe what they particularly liked or disliked about the ordering experience. Further details about any observed critical incidents were also prompted. Second, in line with technology acceptance literature (c.f. Davis 1989), usage-related outcomes (i.e. task-technology fit) were explored (e.g. "What unique elements does Pepper" bring to hospitality service encounters?"). After this, the interview moved to employee-related questions, with particular focus on task allocation and human-robot collaboration (e.g., "What other tasks would you like Pepper" to do in hospitality settings?"). The fourth group of questions took these notions further, and explored the applicability of PepperTM (i.e., concept-technology fit, e.g., "How well do you think Pepper ${ }^{\mathrm{TM}}$ would fit the service concept of your current or previous workplace?"). The fifth and final group of questions leveraged photo elicitation, an interview technique which uses images to guide discussion (Matteucci, 2013). Participants were shown pictures of two alternative, non-humanoid hospitality service robots: a back-of-house robot which assembles complex food items, and a front-of-house robot which is able to not only take orders (like Pepper ${ }^{\mathrm{TM}}$ ) but also facilitate payments, deliver food and drinks, and carry empty plates back to a kitchen. The aim was to tease out how other factors (e.g., increased technical complexity or lack of anthropomorphic features) would impact the adoption of service robots in hospitality contexts.

\subsection{Data Analysis}

Data was analyzed sequentially, whereby the findings from the first service prototype informed the development and design of the second. Qualitative data was analyzed by following the principles of thematic analysis (Braun and Clarke, 2006; 2019). The coding took place in three stages. First, a full read-through of all data was conducted, highlighting any particularly interesting sections and jotting down brief notes in the transcript margins. Then, open coding was conducted (Braun and Clarke, 2006). Altogether, 50 unique codes were identified. In the process, the codes started to naturally form a hierarchical structure consisting of first, second, and third-order codes. This axial coding process (Creswell, 2007) ultimately resulted in five major themes: (1) Suitability, i.e. PepperTM's suitability to carry out specific parts of the service encounter in different use contexts, (2) Agency, i.e. the degree to which Pepper ${ }^{\mathrm{TM}}$ is considered a tool or a member of team, given its capabilities, (3) HRI - Psychological factors, i.e. the various psychological factors that influence Pepper ${ }^{\mathrm{TM}}$ 's integration to hospitality service 
encounters, (4) HRI - Technical factors, i.e. the various technical factors that influence PepperTM's integration to hospitality service encounters, and (5) Acceptability, i.e. factors influencing the overall acceptance of Pepper ${ }^{\mathrm{TM}}$ in hospitality. To ensure the themes adequately captured participants' thoughts, a member's check was conducted, whereby a draft version of the analysis along with a description of each major theme was sent by email to a subsample of participants in Prototype 2 (4 out of 18). All contacted participants gave their support for the analysis, and thus the five themes were deemed to adequately reflect participants' views and the analysis moved on to the next stage of ensuring reliability: peer review.

To ensure analytical consistency, the code book and descriptions of each major theme, along with randomly selected interview excerpts $(N=14)$ were sent by email to two independent peer reviewers for re-coding. The peer reviewers were external to the research study and had different disciplinary backgrounds and demographics (Coder 1: 28 y/o, male, Geography and Smart Tourism, Coder 2: 42 $\mathrm{y} / \mathrm{o}$, male, Hospitality Management). One of the coders (Coder 2) had a good understanding of the topic under study, while the other (Coder 1) had limited knowledge of both the topic and the current study. Following Tuomi, Tussyadiah and Stienmetz (2020), intercoder reliability was determined against two measurements: percent agreement and Cohen's Kappa (Table III). Both tests indicated moderate $(>.41)$, good (>.61), or very good (>.81) agreement between coders (Landis and Koch, 1977). The instances with $<.60$ agreement were discussed in person and addressed on a case-by-case basis with both coders. In all cases the independent coder had been undecided between two closely related codes (representing two different major themes). Consensus was reached through discussion, which resulted in the researchers clarifying the description on two of the five major themes.

\section{PLEASE INSERT TABLE III ABOUT HERE}

\subsection{Findings}

In general, it was found that participants wished Pepper ${ }^{\mathrm{TM}}$ to be used in close tandem with human employees, regardless of the hospitality context: "I think using robots is all fine and well but you need to always have some human interaction too. It can't be at the expense of the human touch" (P3). This overall finding supports Tuomi, Tussyadiah and Stienmetz's (2020) notion of service robots supporting service employees in hospitality settings. More specifically, five major themes were established from the thematic analysis, representing major themes surrounding the application of humanoid service robots as part of hospitality service encounters: (1) Pepper ${ }^{\mathrm{TM}}$ 's suitability to carry out specific parts of the service encounter in different use contexts, (2) Pepper ${ }^{\text {TM's }}$ perceived agency, i.e. the degree to which it is considered a tool or a member of team, given its capabilities, (3) and (4) the various psychological and technical factors that influence PepperTM's integration to hospitality service encounters, and (5) factors influencing the overall acceptance of Pepper ${ }^{\mathrm{TM}}$ in hospitality. Figure III provides a summary of all five major themes.

\section{PLEASE INSERT FIGURE III ABOUT HERE}

\subsection{Suitability}

The suitability of Pepper ${ }^{\mathrm{TM}}$ to effectively deliver service in hospitality contexts was found to be influenced by two dimensions: Pepper ${ }^{\mathrm{TM}}$-Concept fit, i.e., the degree to which Pepper ${ }^{\mathrm{TM}}$ was considered appropriate for different service concepts and types of operation (e.g., quick service, fine dining) aimed at different customer segments (e.g., the elderly, families); and Pepper ${ }^{\text {TM}}$-Task fit, i.e., the degree to which Pepper ${ }^{\mathrm{TM}}$ was able to carry out specific hospitality service tasks. 


\subsubsection{Pepper ${ }^{\mathrm{TM}}$-Concept fit}

In line with Ritzer's (1998) notion of McDonaldization, most participants noted that integrating


type of operation matched the use of service robots. Participants saw that Pepper ${ }^{\mathrm{TM}}$ would work particularly well in quick service or fast casual restaurant settings, as well as in food service establishments aimed at families:

"Can I say an actual restaurant? I'm thinking of like an open plan place. I know this might not be the target, but places like McDonald's, Burger King. I'm not sure about anything high or expensive. Probably something that's quick and easy." (P37)

"I think this will work well in the, like, not necessarily fast food, but like, still sit down but more like a, let's say, the target demographic is the younger audience. I think kids would love to interact with these or you know, parents with kids, they'd love to have this." (P35)

On the other hand, pubs and fine dining were perceived as the least likely settings for introducing Pepper ${ }^{\mathrm{TM}}$, either because of the need to navigate narrow spaces or to provide highly personalized service:

"Let's say a place like a pub. That would be the least useful place because people definitely go there for interaction. And the way pubs are sometimes built doesn't accommodate Pepper ${ }^{\mathrm{TM}}$ 's legs." (P37)

"In a restaurant that's more towards fine dining, though, I think he needs to be a bit more different. [...] I think that he needs to be a bit more responsive, more interactive." (P33)

Finally, the degree to which Pepper ${ }^{\mathrm{TM}}$ was considered a good match with different customer segments (e.g., the elderly) was seen to impact its suitability:

"I think for elderly persons, they might be confused and don't know how to use the system. So, it can be useful, but it depends on the population." (P39)

\subsubsection{Pepper ${ }^{\mathrm{TM}}$-Task fit}

Besides the type of operation, participants were quick to note that Pepper ${ }^{\mathrm{TM}}$ would work better for certain types of tasks over others. Besides welcoming guests or taking orders, other stationary information-provision tasks, such as giving guests directions to the restroom and providing them with the wifi-code, or facilitating payments, were seen as appropriate:

"To me she's just like a signpost; she's telling you where to go." (P34)

"It can have for example a card reader attached. Nowadays all cards are contactless anyway. And you generally pay on the table anyway. So why not through Pepper ${ }^{\mathrm{TM}}$." (P32)

Regardless of task, the importance of human-robot collaboration came through clearly in participants' responses. For example, several participants noted PepperTM's potential to handle customer feedback in tandem with human employees, whereby Pepper ${ }^{\mathrm{TM}}$ could act as a first point-of-contact in case of a complaint: 
"Like, I'm frustrated, and I have to write a feedback for the place, I'll be very nasty. [...] I think you could use Pepper ${ }^{\mathrm{TM}}$ to take the initial shock, and then direct it to a person so that they can double down on whatever problem. I think in a way it helps the waitresses' or the problem managers' well-being because they're not just taking in all the complaints, the initial frustrations. They're just solving the actual problem." (P34)

On the other hand, participants were somewhat sceptic about Pepper ${ }^{\mathrm{TM}}$ 's ability to serve dishes:

"I don't know if it's possible, I don't really know how strong its hands are. They look a bit twitchy." (P35)

"It can take the order, sure, but I wouldn't have it actually serve me." (P5)

\subsection{Agency}

Besides ensuring a good fit between service robot technology and the service concept, target customer, and the robotized task, participants agreed that Pepper ${ }^{\mathrm{TM}}$ primarily supports rather than substitutes service employees in hospitality service. However, the degree to which Pepper ${ }^{\mathrm{TM}}$ was considered an intelligent tool or a member of team with its own "agency" seemed to vary. In social sciences, agency is typically seen to intertwine with the notion of free will, i.e. the ability to act independently and to make free choices (Emirbayer and Mische, 1998). As discussed by Belk (2013), 'objects' have traditionally been seen as passive entities to which humans embed meaning. As objects have become "smarter" - e.g., through increased computational power, memory, or an Internet connection (Mitew, 2014) - they have however started to gain the ability to "affect and be affected" by interacting with users and other objects (Hoffman and Novak, 2017, pp. 1180). On one hand, Pepper ${ }^{\mathrm{TM}}$ is able to exhibit social behavior, for instance respond to simple verbal cues and gestures. On the other, it is not able to express spontaneity or form emotional connections. This limited form of 'affecting' and being 'affected' seemed to puzzle participants:

"I might be critical about these, but in a cafe, we have a lot of equipment or machines already. We don't call them colleagues. We don't communicate with them. Like the coffee machine, or the till. They are there just to help us. Same with this [Pepper $\left.{ }^{\mathrm{TM}}\right]$, except that you can also talk to it. But you wouldn't share your feelings or emotions with it." (P31)

"I think the fear is that robots would replace employees, but I don't think I see it like that. Because there's certain things I believe the robots are not capable of doing just yet. I guess it goes back to the emotional connection." (P37)

"I think she's probably not putting any one job role out of work, but she's putting elements of a job role out of work. And therefore, if you've got a team of 10 people doing a job of which this is a part of, maybe one of them isn't required anymore. [...] I think if you're a supervisor, giving instructions to other people [...] it's going to be part of your role. As long as the robot understands what you're asking it to do, it's just like another employee. But you probably have very set expectations of what that employee could do. Yeah. But you may well with humans as well, particularly when they're new or in training." (P31)

\subsection{Psychological factors}

Related to whether Pepper ${ }^{\mathrm{TM}}$ was perceived as a tool or a colleague were different psychological factors that working with or receiving service from Pepper ${ }^{\mathrm{TM}}$ evoked. From the employee point of view, 
working in service settings that make use of Pepper ${ }^{\mathrm{TM}}$ was seen as cool, unique, or something to be proud of. As put by participants:

"If a restaurant employs robots or whatever, that's something to be proud of, isn't it? Something you tell your friends like, we have a robot now." (P35)

"I think it could be quite fun because who can say they've worked in a restaurant alongside a robot? It's pretty rad. It's very rare. I think personally it would be really fun." (P37)

From the customer point of view, receiving service from Pepper ${ }^{\mathrm{TM}}$ seemed to alleviate feelings of social pressure or judgment, for example with regards to attitudes towards ordering or upselling:

"I think some people might not like to interact with humans. If you have social anxiety or something. Or because you're an introvert. Interacting with a robot might be easier than interacting with humans because he's [the human server] just gonna stand there, looking at me. And I feel pressured to order something. But how I treat a robot, there's a slave connotation to it. You can take all the time you want, it won't judge you." (P32)

"If I go to McDonald's, and the kiosk gives a prompt when I'm ordering, like do you want to add this dip to your order, I don't think there's a problem there. It's not like the level of service is so exquisite anyway. It's maybe even worse when an employee asks you those questions, you feel guilty answering even if you want it. [...] If it's just on a machine, it's fine, no one is trying to push it on you. It's just there. [...] Sometimes when the employee asks you, you don't really even want it, but they're just being so nice, you feel like you're being pushed into it. Just to be nice. You're gonna get something not because you want it but because you want to be nice. But with a robot he's not gonna judge you." (P35)

\subsection{Technical factors}

Besides psychological factors, the way in which participants interacted with Pepper $^{\mathrm{TM}}$ was also underlined by technical factors, that is, PepperTM's technical capabilities. In particular, Pepper ${ }^{\text {TM's }}$ comprehension and intent recognition (i.e., the accuracy of its natural language processing software), Pepper ${ }^{\mathrm{TM}}$ 's position and movement within the servicescape, as well as the tablet user-interface and its responsiveness were found to play a key role in the HRI. As noted by participants:

"I think it definitely had a problem with my accent. I probably talk a bit fast anyway, and then there's my accent, which is not British..." (P33)

"I think in a situation like this, I would like the robot to come to me, take my order and then go away." (P34)

"Ordering kiosks that I've used before have been quite mundane. It's a one-way interaction between you and that screen. The fact that she $\left[\right.$ Pepper $\left.^{\mathrm{TM}}\right]$ is producing slightly more than that is great, because it adds another level of complexity or interaction to the step. I think getting the natural language processing right would probably be quite tricky, although I guess $90 \%$ of the questions that are asked are the same." (P31)

"I like the fact that she had arm movements as well. Though, when I was looking at the tablet, I pressed the button, and it took a couple of seconds for it to react." (P33) 


\subsection{Acceptability}

Finally, participants noted factors influencing the acceptability of service robots in hospitality more generally. Technological progress, customer expectations, costs, and a shifting focus towards tasks and ultimately, jobs, that involve creativity, problem solving, and emotional intelligence rather than repetitive, manual tasks were discussed. Overall, the prospect of robotization was seen in a relatively positive light:

"Everything's moving to technology anyway. I don't think systems like this are meant to be harmful. I think it's meant to make things more productive, make things easier. Working in the service industry is hard enough as it is. [...] I don't think this makes your work less stressful, but I think it shifts your priorities. And maybe if something like this exists, you can engage more with the customer. And you don't have to worry about the order being done wrong. And you don't have to have an aggressive customer speak to you." (P37)

"I hope that this type of technology will expand more. It's not like we don't like waiters and waitresses, we do. But we understand that they do a very hard job. And much of the time, like most of the time, what they're doing is very repetitive and can be very tiring and boring." (P33)

Besides general optimism towards technological progress, participants also noted how there might be barriers to adoption, such as negative attitudes towards robots or glitches. In addition, few participants also pointed out how the novelty of service robots might fade over time:

"At the beginning there may be some reluctance to work with it. Until you see how efficient or not it can be to fulfil the task. Because if I gave him tasks, and then I have to redo it because it's not done properly, I would be pissed off. But on the other hand, if it can release my stress and take care of the tasks I don't want to do, I would be very happy. (P39)

"Maybe at first you go two or three times because there's a robot. But then if it's in your close proximity you just go and that's how you order there." (P33)

\subsection{Discussion and Conclusions}

\subsection{Conclusions}

Empirical studies looking at the implementation and impacts of service robots in hospitality service encounters are still scant. While extant studies have started to present theory-driven conceptualizations of behavior or empirical studies exploring behavioral intention, this study took on a more inductive approach (Locke, 2007), and explored direct HRI with a specific humanoid robot, PepperTM, in two hospitality service prototypes: 1) as a receptionist during an academic conference and 2) as a server in a simulated restaurant. The study sought to shed light on the suitability of anthropomorphized robots in the specific use-setting of hospitality, focusing particularly on the operational and customer experience implications of introducing Pepper ${ }^{\mathrm{TM}}$. In essence, Pepper ${ }^{\mathrm{TM}}$ seems most suitable for carrying out simple service tasks in relatively scripted service environments characterized by low expectations of service quality, e.g. in quick service. This finding is in line with Ritzer's (1998) theory of McDonaldization, and also corresponds with Huang and Rust's $(2018 ; 2021)$ theory of service work replacement. Building on affordances of other self-service technologies that are already in use in hospitality, Pepper ${ }^{\mathrm{TM}}$, due to its anthropomorphic design and wide array of sensors, is able to bring several novel features to the human-technology interaction. The next two chapters discuss these in detail. 


\subsection{Theoretical Implications}

Using a humanoid service robot to deliver service in hospitality poses considerations across several dimensions: contextual, social, interactional, and psychological. In essence, integrating humanoid service robots as part of the service production and delivery system changes the conventional dynamics and relationships between service organizations, service employees, and customers. Empirical results here illustrate how adopting a specific robot transforms this service triad, from task distribution to employee and customer experience. Based on these findings, design principles for integrating humanoid service robots in hospitality service encounters can be conceptualized. In their work, Murphy, Gretzel and Pesonen (2019) conceptually explored how robot anthropomorphism shapes human-robot interaction in robot service (rService). In a similar vein, Belanche, Casaló and Flavián (2020a; 2020b; $2020 \mathrm{c}$ ) explored several specific features of anthropomorphism in customer-robot service interaction, from willingness-to-use and recommend humanoid service robots to how responsibility is attributed between different actors of the service triad in successful or failed service encounters. Combining previous work in this space with empirical findings from two service prototypes, and drawing from seminal theories on organizational management (McDonaldization, Job Design Theory) and humanrobot interaction (Uncanny Valley Theory), we propose design principles for Humanoid Robot Adoption in Hospitality Service Encounters: HuRA-HSE (Figure IV). HuRA-HSE offers an important theoretical contribution to hospitality by illustrating the multi-layered process of introducing a humanoid service robot in hospitality service encounters. In doing so, HuRA-HSE provides novel contextual insight on human-robot interaction in the ecosystem (that is, hospitality service encounters) within which the contextual usage is situated (Kar and Dwivedi, 2020).

\section{PLEASE INSERT FIGURE IV ABOUT HERE}

First, adopting humanoid service robots in hospitality service encounters is suggested to be driven by both extrinsic and intrinsic factors. Extrinsic factors identified herewith relate to innovation diffusion, that is, the pace at which novel technology is developed and technological progress diffused across a sector (Rogers, 1995), as well as customer expectations of convenience and memorable new service experiences. Intrinsic factors relate to leveraging technology to increase the 'decency' of hospitality employment (Tuomi et al., 2020), as well as reduce service variability through standardization. Besides extrinsic and intrinsic factors, humanoid robot adoption in hospitality service encounters is also influenced by contextual, social, interactional, and psychological layer. Contextual layer depicts the robots' use-context in relation to service concept and service task; social layer illustrates robots' perceived agency and determining the locus of control between the service employee and the service robot; interaction layer consists of the technological dimensions at play in HRI, i.e. adopted tone of voice, use of gestures, mobility, robot responsiveness, and robots' ability to recognize intent; and the psychological layer captures psychological drivers of behavior in humanoid robot service interaction, that is, social pressure and social judgment (as seen from the customer point of view) and peer recognition (as seen from the employee point of view).

Drawing from Hackman and Oldham's (1980) Job Design Theory, the design principles suggested herewith illustrate 'robot-job fit', a novel concept which aims to determine the balance between different factors that influence successful service interaction in the context of robotized hospitality service encounters. Separating between robot-job fit and person-job fit is imperative in order to adopt "intelligent" technology, such as humanoid service robots, in a way that makes the best use of both robot and human capability but reflect human, not robot, values (Grover, Kar, Dwivedi, 2020). Offering hospitality and HRI scholars with a solid base to build further studies on, HuRA-HSE is suggested as a 
theory-informed, normative conceptualization for humanoid robot adoption in hospitality service encounters.

\subsection{Practical Implications}

As discussed by Ritzer (1998), streamlining or downright automating processes in service production and delivery is typically associated with quick service. In line with this reasoning, participants in this study emphasized quick service or fast casual restaurants over fine dining as most suitable hospitality contexts for Pepper ${ }^{\mathrm{TM}}$. This is influenced by both customer expectations and Pepper ${ }^{\mathrm{TM}}$ 's technical capabilities. First, as discussed by Brinck and Balkenius (2020), to achieve natural HRI a service robot needs to adapt and react to its environment and the behavioral patterns of its conversational partner. In theory, Pepper ${ }^{\mathrm{TM}}$ is able to track movement and facial expressions through its suite of sensors; in practice getting for example its facial recognition package to work has proven difficult (Perera et al., 2017). Same holds true for its natural language processing capabilities. Pepper ${ }^{\mathrm{TM}}$ seems to be most suitable for providing standardized information in response to simple stimuli, e.g. short keywords instead of complex sentences or one speaker instead of overlapping speech. Pepper ${ }^{\mathrm{TM}}$ can therefore add some dimensionality to other self-service technologies already used by providers by utilizing different interaction cues (voice, touch, movement), especially when used in relatively quiet settings, e.g. a corner table. However, in its current state Pepper ${ }^{\mathrm{TM}}$ cannot cope well with complexity or sensory overload. Constrained by its relatively outdated components, Pepper ${ }^{\mathrm{TM}}$ often slows down or crashes when trying to fuse data from multiple sensors. To mitigate for this, service operators should carefully consider which type of sensor data is most relevant for their particular need (i.e., use-context and service encounter/task type), as well as clearly communicate the robot's degree of "intelligence" to customers and employees (Belanche, Casaló and Flavián (2020b).

Besides technical feasibility, customers may also hold different expectations in terms of service depending on the type of service concept. In general, concepts that focus on quantity over quality tend to be characterized as low-touch, meaning the service encounter itself is not perceived to hold much value and is therefore often standardized or 'McDonaldized' (Davis et al., 2018). This contrasts with concepts that place great importance on the service encounter and its quality, resulting in a more laborintensive high-touch characterization. Frontline self-service technologies, and indeed Pepper ${ }^{\mathrm{TM}}$, are more suitable for settings where expectations of service quality are relatively low. At the lowest end of the spectrum Pepper ${ }^{\mathrm{TM}}$ can be seen as an appropriate substitution for highly scripted human service or an existing self-service system. On the other hand, in medium- or high-touch service concepts, where expectations are typically higher, a collaborative effort is suggested, with Pepper ${ }^{\mathrm{TM}}$ taking care of the most routine service encounters (i.e., tasks that fall on the lower levels of Huang and Rust's (2018) service task intelligence framework, e.g., repeat orders) and a service employee focusing on the more complex encounters (i.e., tasks that involve intuitive or empathetic intelligence e.g. dealing with a complaint).

Besides its technical capabilities, Pepper ${ }^{\mathrm{TM}}$ 's physical appearance may also have implications on how it is adopted in hospitality service encounters. Pepper ${ }^{\mathrm{TM}}$ is a highly anthropomorphized service robot, with several human-like features, including a head, face, torso, hands, as well as joint movement and gestures. However, it is still clearly a robot and not a human, thus positioning it outside of Mori's (1970) Uncanny Valley. Looking at robot-use in hotels, Tussyadiah and Park (2017) found anthropomorphism as particularly important for adopting service robots that interact directly with customers, while Lv et al. (2021) emphasize the impact of "cuteness" on AI-assistant adoption in service contexts. Human-like features may evoke emotional responses such as feelings of familiarity or attachment (Murphy, Gretzel and Pesonen, 2019). In this study, participants frequently referred to Pepper"TM as a "he" or a "she" 
rather than an "it". In addition to familiarity, several participants also attributed working in a restaurant that uses Pepper ${ }^{\mathrm{TM}}$ to feelings of proudness or uniqueness. Technology acceptance literature has long since noted the effect of "social influence" on acceptance (Davis, 1989), with recent studies on service robot adoption in tourism starting to explore this too (c.f. Hou, Zhang and Li, 2021). Tapping into feelings of familiarity or peer-recognition might make it easier for hospitality service operators to introduce humanoid robots over other forms of technologies.

However, despite Pepper ${ }^{\mathrm{TM}}$ 's human-likeness, its actual ability to exhibit different forms of intelligence is still limited. Drawing on the service task intelligence framework by Huang and Rust $(2018 ; 2021)$, Pepper ${ }^{\mathrm{TM}}$ is able to carry out tasks requiring mechanical or analytical intelligence, but it cannot display intuitive or empathetic intelligence. From an operations point of view, Pepper ${ }^{\mathrm{TM}}$ is therefore more akin to an interactive tool than a full member of staff, and acts as an extension, rather than a replacement, of employees' physical and mental capabilities in a limited domain of tasks. In addition to adding new dimensions to the service encounters of welcoming guests or taking orders, Pepper ${ }^{\mathrm{TM}}$, due to its humanlike social presence, may also prove useful in other parts of the service process. For instance, allowing customers to pay on their own may increase table turnover (Gaskill, 2015). However, Khalilzadeh, Ozturk and Bilgihan (2017) found that some customers dislike the idea of paying at the table, and that trust, risk, and security plays an important role in the intention to use tableside payment systems. Cocosila and Trabelsi (2016) argue that the perceived gain of introducing tableside payments, versus their perceived costs such as increased liability, ultimately determine how customers adopt paying at the table. In their work, van Pinxteren et al. (2019) found that service robot anthropomorphism had a positive effect on trust, enjoyment, and intention-to-use. Using Pepper ${ }^{\mathrm{TM}}$ to help customers go through the payment process might improve tableside payment adoption, especially if rapport has already been built by using Pepper ${ }^{\mathrm{TM}}$ in earlier parts of the customer journey.

\subsection{Limitations and Future Research}

As is the case with all research, there are several limitations and future research directions that should be considered. First, in both of the service prototypes conducted here Pepper ${ }^{\mathrm{TM}}$ was used in a stationary manner, i.e. participants came to it rather than it navigating to participants' location. This was due to the limitations of Pepper ${ }^{\mathrm{TM}}$ 's built-in operational framework, NAOqi, which has proven problematic for autonomous navigation (Suddrey, Jacobson and Ward, 2018). Even though a stationary approach was a good task-technology fit for the types of service encounters explored here, an integrated approach leveraging the robot operating system is suggested especially for exploring service encounters that rely on movement (e.g. escorting guests to a table) (Perera et al., 2017). Including an element of movement to the encounters of welcoming and ordering might also yield new insight.

Besides looking at the use of Pepper ${ }^{\mathrm{TM}}$ in different use-scenarios and with different capabilities, further research should also explore the use of different types of service robots. Through leveraging photo elicitation, this study started to probe at the suitability of using other, non-humanoid service robots in hospitality service encounters. However, rather than aiming for participants' perceptions of use, further research should explore actual usage of non-humanoid robots in hospitality service. Another widely available service robot suitable for these types of studies would be Savioke's Relay.

Finally, the psychological implications of interacting with a service robot rather than a service employee in hospitality service warrant further research. Previous studies have made important steps in understanding how service robots might nudge guests towards particular behavioral outcomes (Tussyadiah and Miller, 2019). Building on this, future studies could compare the average spend per customer when ordering with a service robot or a service employee, as well as the relative impact of 
upselling. Another interesting avenue of research would be service failure and complaint behavior, e.g. how do customers cope with mistakes (wrong orders, inaccurate bills) in human-human interaction versus HRI? Similarly, how does giving feedback (positive or negative) differ when the recipient is a human or a robot? From the employee point of view, which factors affect (e.g. diminish or enhance) perceived peer recognition (e.g. 'coolness') resulting from service robot adoption? Overall, future research in this area should endeavor to consciously shift the focus of HRI studies from looking at behavioral intention to exploring actual behavior in hospitality contexts in order to elicit richer theoretical debate and more actionable practical insight.

\section{References}

Ashcroft, E., Tuomi, A., Wang, M., Solnet, D. (2019). "Resistance to the adoption of ICTs in independent restaurants: insights from China and the UK," e-Review of Tourism Research (16/2-3), pp. 105-114.

Baum, T. (2015). Human resources in tourism: Still waiting for change? - a 2015 reprise. Tourism Management 50, 204-212.

Belanche, D., Casaló, L., Flavián, C. \& Schepers, J. (2019). Service robot implementation: a theoretical framework and research agenda. The Service Industries Journal, pp. 1-23.

Belanche, D., Casaló, L. \& Flavián, C. (2020a). Frontline robots in tourism and hospitality: service enhancement or cost reduction? Electronic Markets. DOI: 10.1007/s12525-020-00432-5.

Belanche, D., Casaló, L. \& Flavián, C. (2020b). Robots or frontline employees? Exploring consumers' attributions of responsibility and stability after service failure or success. Journal of Service Management 31(2), pp. 267-289.

Belanche, D., Casaló, L. \& Flavián, C. (2020c). Customer's acceptance of humanoid robots in services: the moderating role of risk aversion. In: Marketing and Smart Technologies, Rocha, A. et al. (Eds.), pp. 449-458. Singapore: Springer.

Belk, R. (2013). Extended Self in a Digital World. Journal of Consumer Research 40(3), pp. 477-500.

Braun, V., Clarke, V. (2006). Using thematic analysis in psychology. Qualitative Research in Psychology 3(2), pp. 77-101.

Braun, V., Clarke, V. (2019). To saturate or not to saturate? Questioning data saturation as a useful concept in thematic analysis and sample-size rationales. Qualitative Research in Sport, Exercise and Health, pp. 1-16.

Brinck, I., Balkenius, C. (2020). Mutual recognition in human-robot interaction: a deflationary account. Philosophy \& Technology 33, pp. 53-70.

Choi, S., Mattila, A., Bolton, L. (2020). The err is human(-oid): How do consumers react to robot service failure and recovery? Journal of Service Research. DOI: 10.1177/1094670520978798.

Cocosila, M., Trabelsi, H. (2016). An integrated value-risk investigation of contactless mobile payments adoption. Electronic Commerce Research and Applications. DOI: 10.1016/j.elerap.2016.10.006. 
Creswell, J. (2007). Qualitative Inquiry \& Research Design. 2nd ed. Thousand Oaks: Sage.

Davis, F. (1989). Perceived usefulness, perceived ease-of-use, and user acceptance of information technology. MIS Quarterly 13(3), pp. 319-323.

Davis, B., Lockwood, A., Alcott, P. and Pantelidis, I. (2018). Food and Beverage Management. $6^{\text {th }}$ ed. London: Routledge.

Emirbayer, M., Mische, A. (1998). What is agency? American Journal of Sociology 103(4), pp. 9621023.

Gaskill, T. (2015). Turning the Tables. Quality Progress 48(8), pp. 10-12.

Grover, P., Kar, A. K., \& Dwivedi, Y. K. (2020). Understanding artificial intelligence adoption in operations management: insights from the review of academic literature and social media discussions. Annals of Operations Research, pp. 1-37.

Gursoy, D., Chi, O., Lu, L., Nunkoo, R. (2019). Consumers acceptance of artificially intelligent (AI) device use in service delivery. International Journal of Information Management 49, pp. 157-169.

Hackman, R., Oldham, G. (1980). Work redesign. Reading: Addison-Wesley.

Herzberg, F., Mausner, B., Snyderman, B. (1959). The motivation to work. London: John Wiley \& Sons.

Hoffman, D.L., \& Novak, T.P. (2018). Consumer and object experience in the internet of things: An assemblage theory approach. Journal of Consumer Research, 44(6), pp. 1178-1204.

Hou, Y., Zhang, K., Li, G. (2021). Service robots or human staff: How social crowding shapes tourist preferences. Tourism Management 83, 104242.

Huang, M. H., \& Rust, R. (2018). Artificial Intelligence in service. Journal of Service Research, 21(2), $155-172$.

Huang, M-H., Rust, R. (2021). A strategic framework for artificial intelligence in marketing. Journal of the Academy of Marketing Science 49, pp. 30-50.

Ivanov, S., Webster, C. (2019). Robots in tourism: A research agenda for tourism economics. Tourism Economics. DOI: 10.1177/1354816619879583.

Jones, S. (1992). Was there a Hawthorne effect? American Journal of Sociology 98(3), 451-468.

Kar, A. K., \& Dwivedi, Y. K. (2020). Theory-building with big data-driven research-Moving away from the "What" towards the "Why". International Journal of Information Management, 54, 102205. 
Khalilzadeh, J., Ozturk, A., Bilgihan, A. (2017). Security-related factors in extended UTAUT model for NFC based mobile payment in the restaurant industry. Computers in Human Behaviour 70, pp. 460474.

Landis, J. R., \& Koch, G. G. (1977). The measurement of observer agreement for categorical data. Biometrics, 33, 159-174.

Liedtka, J. (2011). Learning to use design thinking tools for successful innovation. Strategy \& Leadership 39(5), pp. 13-19.

Lin, I. \& Mattila, A. (2010). Restaurant servicescape, service encounters, and perceived congruency on customers' emotions and satisfaction. Journal of Hospitality Marketing \& Management 19, pp. 819841.

Locke, E. A. (2007). The case for inductive theory building. Journal of Management, 33(6), pp. 867890 .

Lu, L., Zhang, P., Zhang, T. (2021). Leveraging "human-likeness" of robotic service at restaurants. International Journal of Hospitality Management 94, 102823.

Lv, X., Liu, Y., Luo, J., Liu, Y., Li, C. (2021). Does a cute artificial intelligence assistant soften the blow? The impact of cuteness on customer tolerance of assistant service failure. Annals of Tourism Research 87, 103114.

Marsh, K. L., Meagher, B. R. (2016). Affordances and interpersonal coordination. In: Passos, P., Chow, J. Y., Davids, K. (eds.), Interpersonal coordination and performance in social systems, London: Routledge.

Matteucci, X. (2013). Photo elicitation: Exploring tourist experiences with researcher-found images. Tourism Management 35, pp. 190-197.

Mitew, T. (2014). Do Objects Dream of an Internet of Things? Fibreculture Journal 23, pp. 1-26.

Mori, M. (1970). The Uncanny Valley. Energy 7(4), pp. 33-35.

Murphy, J., Gretzel, U., \& Pesonen, J. (2019). Marketing robot services in hospitality and tourism: The role of anthropomorphism. Journal of Travel \& Tourism Marketing, 36, 784-795.

Oldham, G., Fried, Y. (2016). Job design research and theory: past, present and the future. Organizational Behavior and Human Decision Processes 136, pp. 20-35.

Onyeulo, E., Gandhi, V. (2020). What makes a social robot good at interacting with humans? Information 11(43), pp. 1-13.

Pandey, A., Gelin, R. (2018). A mass-produced sociable humanoid robot. IEEE Robotics \& Automation Magazine, September, pp. 40-48. 
Perera, V., Pereira, T., Connell, J., Veloso, M. (2017). Setting Up Pepper For Autonomous Navigation And Personalized Interaction With Users. arxiv:1704.04797.

Ritzer, G. (1998). The McDonaldization thesis: explorations and extensions. London: Sage.

Rodgers, P. and Milton, A. (2011). Product Design. London: Laurence King Publishing.

Rogers, E. (1995). Diffusion of Innovations. 4th ed. London: Free Press.

Rubio, F., Valero, F., Llopis-Albert, C. (2019). A review of mobile robots: Concepts, methods, theoretical frameworks, and applications. International Journal of Advanced Robotic Systems, MarchApril, pp. 1-22.

Suddrey, G., Jacobson, A., Ward, B. (2018). Enabling a Pepper Robot to provide Automated and Interactive Tours of a Robotics Laboratory. IEEE International Conference on Intelligent Robots.

Tung, V. \& Au, N. (2018). Exploring customer experiences with robotics in hospitality. International Journal of Contemporary Hospitality Management 30(7), 2680-2697.

Tuomi, A., Tussyadiah, I., Ling, E.C., Miller, G., Lee, G. (2020). x=(tourism_work) y=(sdg8) while $\mathrm{y}=$ true: automate(x). Annals of Tourism Research, 84, DOI: 10.1016/j.annals.2020.102978.

Tuomi, A., Tussyadiah, I., Stienmetz, J. (2020). Applications and implications of service robots in hospitality. Cornell Hospitality Quarterly. DOI: 10.1177/1938965520923961.

Tussyadiah, I. (2020). A review of research into automation in tourism: Launching the Annals of Tourism Research Curated Collection on artificial intelligence and robotics in tourism. Annals of Tourism Research 81.

Tussyadiah, I., Miller, G. (2019). Nudged by a robot: Responses to agency and feedback, Annals of Tourism Research. DOI: 10.1016/j.annals.2019.102752.

Tussyadiah, I., Park, S. (2017). Consumer evaluation of hotel service robots. In Stangl, B., \& Pesonen, J. (Eds.), Information and communication technologies in tourism 2018 (pp. 308-320). Springer.

UKHospitality. (2020). Future Shock Issue Five. Available at: https://www.ukhospitality.org.uk/page/FutureShock-IssueFive (Accessed 25th May 2020).

van Pinxteren, M., Wetzels, R., Rüger, J., Pluymaekers, M., Wetzels, M. (2019). Trust in humanoid robots: implications for services marketing. Journal of Service Marketing 33(4), pp. 507-518.

Wirtz, J., Patterson, P., Kunz, W., Gruber, T., Lu, V., Paluch, S. \& Martins, A. (2018). Brave new world: service robots in the frontline. Journal of Service Management 29(5), pp. 907-931. 
Spicing Up Hospitality Service Encounters: The Case of Pepper ${ }^{\mathrm{TM}}$

Figure I. The Setting for Service Prototype 1: Receptionist

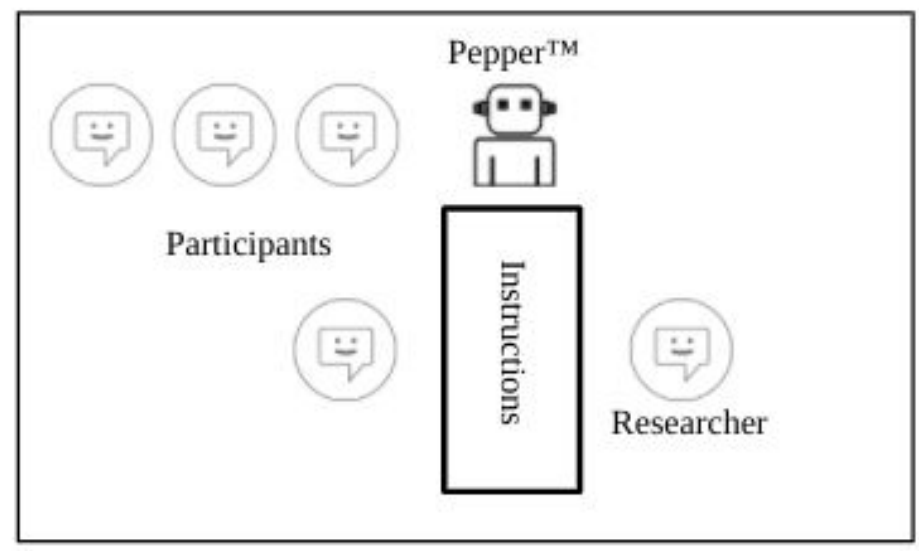

Figure II. The Setting for Service Prototype 2: Server

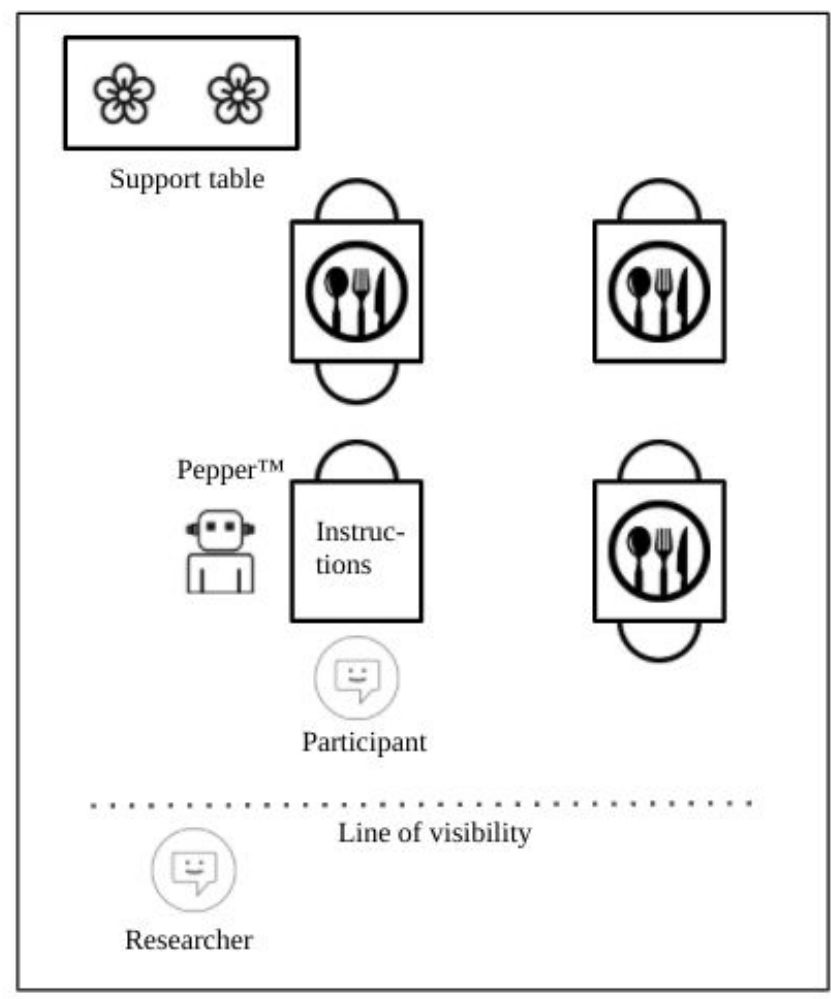


Figure III. Summary of Major Themes

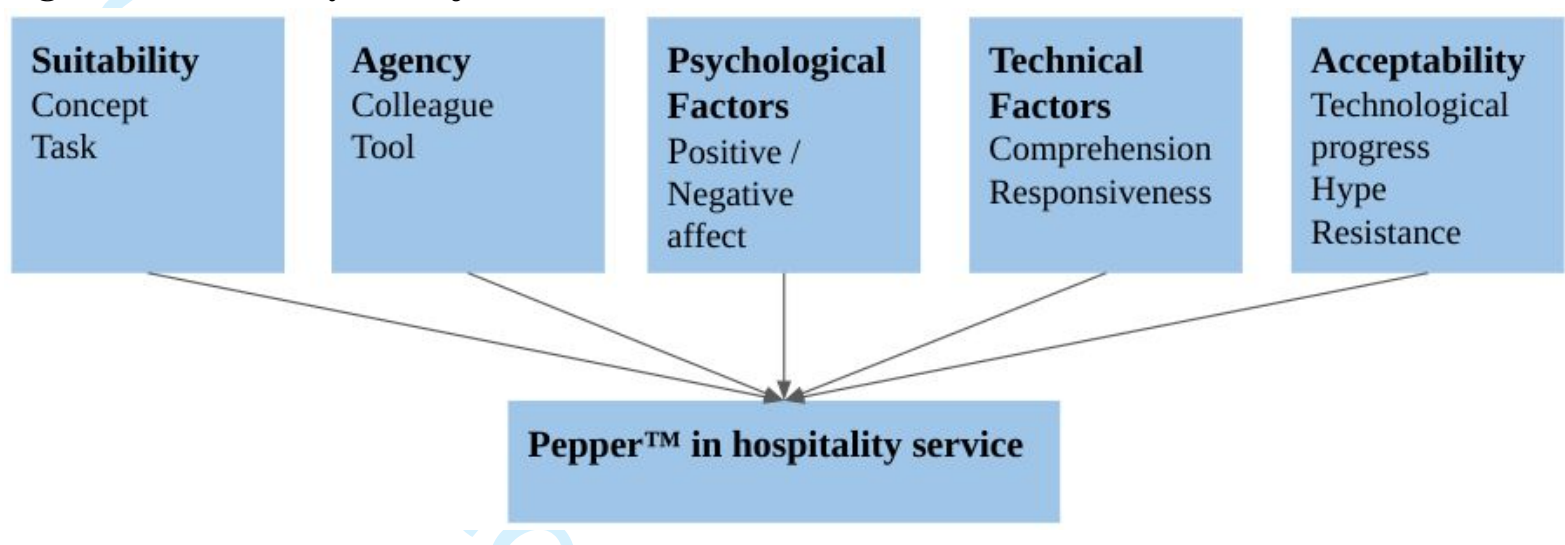

Figure IV. Design Principles for Humanoid Robot Adoption in Hospitality Service Encounters

(HuRA-HSE)

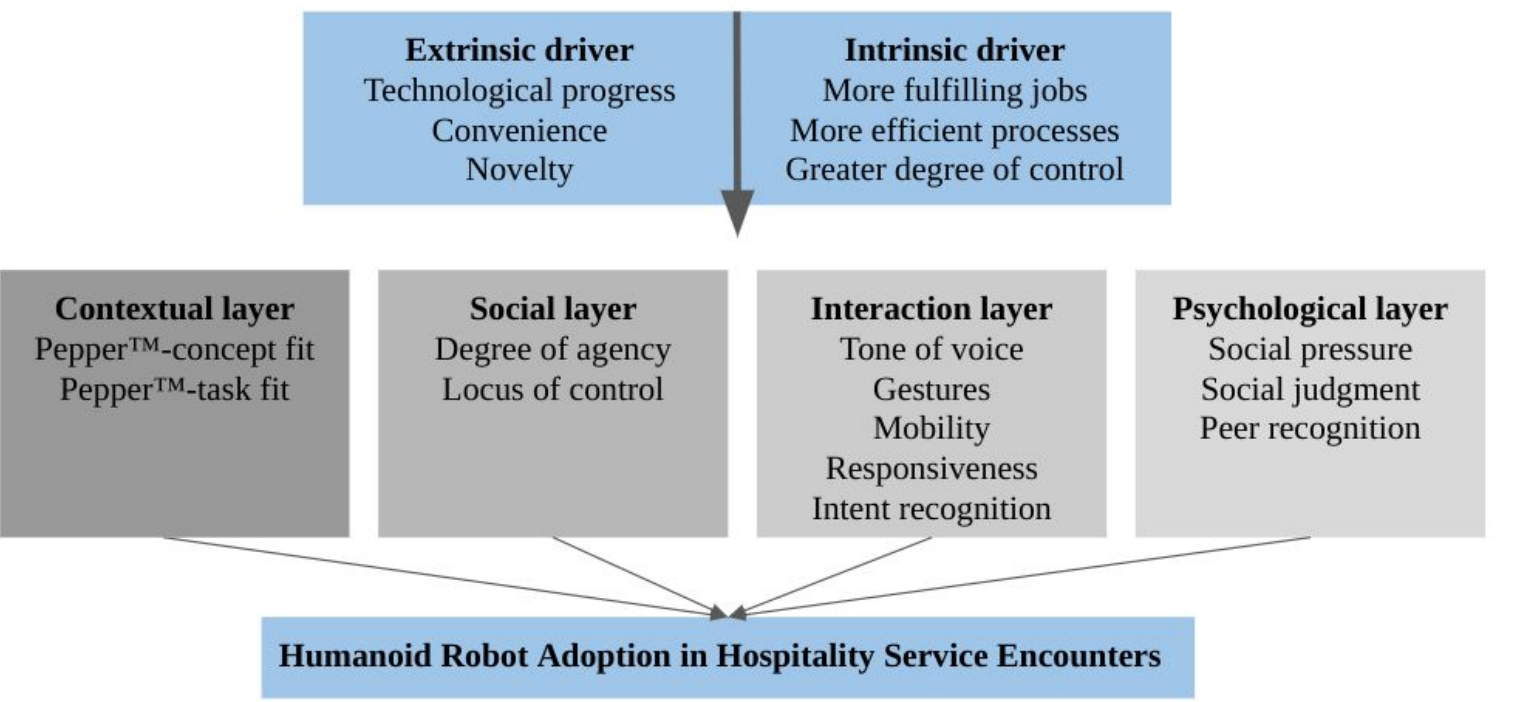


Spicing Up Hospitality Service Encounters: The Case of Pepper ${ }^{\mathrm{TM}}$

Table I. Participants in Service Prototype 1: Receptionist $(N=30$, Female $=43 \%)$

\begin{tabular}{ccc|ccc} 
ID & Gender & Age & ID & Gender & Age \\
\hline P1 & Female & $18-24$ & P16 & Male & $35-44$ \\
P2 & Male & $18-24$ & P17 & Male & $35-44$ \\
P3 & Male & $25-34$ & P18 & Female & $25-34$ \\
P4 & Male & $25-34$ & P19 & Male & $25-34$ \\
P5 & Male & $35-44$ & P20 & Male & $45-54$ \\
P6 & Female & $45-54$ & P21 & Female & $45-54$ \\
P7 & Male & $35-44$ & P22 & Female & $25-34$ \\
P8 & Male & $45-54$ & P23 & Female & $25-34$ \\
P9 & Female & $18-24$ & P24 & Male & $35-44$ \\
P10 & Female & $18-24$ & P25 & Male & $35-44$ \\
P11 & Female & $18-24$ & P26 & Male & $25-34$ \\
P12 & Female & $25-34$ & P27 & Female & $65+$ \\
P13 & Male & $55-64$ & P28 & Male & $25-34$ \\
P14 & Male & $45-54$ & P29 & Male & $55-64$ \\
P15 & Female & $35-44$ & P30 & Female & $35-44$ \\
\hline & & & & \\
\hline
\end{tabular}


Table II. Participants in Service Prototype 2: Server $(N=18$, Female $=39 \%)$

\begin{tabular}{|c|c|c|c|c|c|}
\hline ID & Gender & Age & ID & Gender & Age \\
\hline P31 & Male & $35-44$ & $\mathrm{P} 40$ & Male & $35-44$ \\
\hline P32 & Male & $18-24$ & P41 & Male & $18-24$ \\
\hline P33 & Female & $18-24$ & P42 & Male & $25-34$ \\
\hline P34 & Male & $25-34$ & P43 & Male & $18-24$ \\
\hline P35 & Male & $18-24$ & P44 & Female & $18-24$ \\
\hline P36 & Female & $18-24$ & P45 & Male & $18-24$ \\
\hline P37 & Female & $25-34$ & P46 & Female & $25-34$ \\
\hline P38 & Female & $25-34$ & P47 & Female & $25-34$ \\
\hline P39 & Male & $18-24$ & P48 & Male & $35-44$ \\
\hline
\end{tabular}

